\title{
Efficiency of Universities: Drivers, Enablers and Limitations
}

\author{
Veronika Kupriyanova, Thomas Estermann and Norbert Sabic
}

\section{Introduction}

\section{Background and Objectives}

Since the significant economic downturn arising from the global crisis in 2008, there has been increasing interest from policymakers and higher education institutions in Europe about efficiency and effectiveness in the higher education context. The growing attention to these topics has also been triggered by changes in funding modalities and in university governance and accountability frameworks, as well as growing competition among higher education institutions and the evolving student body. Against this background, two important questions arise for higher education practitioners and researchers: first, how could universities achieve their core institutional goals while ensuring the efficiency of their processes and operations, and secondly, what kind of framework conditions could support universities in their quest for efficiency and effectiveness?

To help institutions and policymakers address these questions, the European University Association (EUA), together with its partners, initiated a project called

\footnotetext{
V. Kupriyanova $(\bowtie) \cdot T$. Estermann

European University Association, Brussels, Belgium

e-mail: Veronika.Kupriyanova@eua.eu

T. Estermann

e-mail: thomas.estermann@eua.eu

N. Sabic

Central European University, Budapest, Hungary

e-mail: norbert.sabic@outlook.com

(C) The Author(s) 2018
}

A. Curaj et al. (eds.), European Higher Education Area: The Impact of Past and Future Policies, https://doi.org/10.1007/978-3-319-77407-7_36 
Universities for Strategic, Autonomous and Efficient Management (USTREAM). ${ }^{1}$ The aim of the project is to elaborate recommendations on ways to enhance efficiency in university management and support the creation of enabling policy frameworks. This paper is based on the selected findings and data collected by the USTREAM project. It explores both system-level and institutional factors that affect the design and implementation of the efficiency agendas, drawing on the efficiency experience of more than 100 higher education institutions across Europe.

\section{Methods and Structure of the Study}

This paper relies on the qualitative and quantitative data collected from a number of sources. Desk research and review of theoretical and specialised literature are presented in the first section of the study. This part also outlines a general analytical framework for the study and analysis of efficiency measures. The second section provides an overview of institutional practices and institutional trends in efficiency activities based on an online survey conducted by the USTREAM partners. In total, 68 higher education institutions from 21 countries reported during the autumn of 2016 on their efficiency practices. Most of the respondents were from Poland (9), Czech Republic (7), Ireland (7), Spain (6), and the United Kingdom (6). The majority (17) were small institutions with an annual budget below 20 million euros, less than 7500 students, and staff below 1000. At the other end of the scale, a similar number of institutions (12) had budgets over 100 million euros, more than 25,000 students, and staff above 3000 members. Although there is a fairly equal distribution of institutions based on student numbers and faculty size, institutions with a budget over 100 million euros were slightly overrepresented in our sample.

In addition to the survey, three site visits were organised to Austria, Flanders/ Belgium and Poland in order to collect qualitative data. As part of these visits, three focus groups were conducted with the representatives of 10 universities (vice-rectors, finance directors), and three interviews were held with the high-level national policymakers from these countries. This qualitative data was complemented by further institutional and system-level evidence collected during a series of meetings with national rectors' conferences and at a peer learning seminar on national and institutional frameworks for efficiency and effectiveness. The seminar was organised by EUA and Universities UK on 1 and 2 June 2017 in London, with the aim to enable sharing of institutional experiences in efficiency and effectiveness. The event was attended by 32 university leaders and managers from 13 countries across Europe.

\footnotetext{
${ }^{1}$ The USTREAM project is co-funded by the Erasmus + Programme of the EU and implemented by the European University Association, Universities UK, the Irish Universities Association and the Central European University. For more details, please see www.eua.eu/ustream.
} 
The final part of the paper summarises the main findings and core conclusions drawn from the data sources mentioned above.

\section{Analytical Framework and Approach}

\section{Understanding Efficiency in Higher Education}

\section{The Rise of the Efficiency Discourse}

Efficiency started to be discussed more specifically in higher education following the severe cuts in public expenditure across a number of developed countries during the 1980s (Peters 1992). Combined with the rapidly increasing number of students in the same period, it contributed to a deeper concern for how higher education institutions perform. Efficiency became a central policy concern as governments sought to satisfy the increased demand for higher education with the same or less level of funding. Exacerbated by cases where efficiency was "punished" by public funders through a mirroring reduction in allocated resources, such policy orientations led to a situation where the term acquired a rather negative connotation within the sector. Hence, it is not surprising that efficiency has started to be associated with funding cuts and the related negative effects (e.g. staff layoffs). As a result, concepts such as effectiveness, value for money and qualitative monitoring were proposed as more suitable to the specific character of universities that are driven by spirit, passion and intrinsic motivation.

The value of efficiency has been reinstated with the uptake of new public management principles in higher education (Broucker et al. 2015). In the spirit of the "entrepreneurial university" (Clark 1998), some institutional leaders have lately started to associate efficiency with pragmatic gains that can be achieved from expanded investment opportunities as well as increased opportunities to close the gap between rising costs, new tasks and limited budgets.

\section{Diversity of Approaches}

Despite growing concerns about efficiency in higher education, there is a limited conceptual, methodological, or policy clarity in this area, which is due to several factors. First, applying the concept of efficiency in higher education is generally problematic due to the unique nature of the university mission, linked to its socio-economic goal, types of institutions, method of financing, and the diversity of beneficiaries involved with higher education (Sadlak 1978). Second, both the interest in and understanding of efficiency significantly vary across different higher education systems, institutions and their units. Different perceptions of efficiency reflect so-called internal and external institutional diversity, as institutions have 
different cultures, historical backgrounds, frameworks and ways of providing teaching, research and services (Reichert 2009).

The results of the USTREAM survey confirm a great diversity of approaches to efficiency across the systems, institutions and individuals. When asked about how efficiency is understood at the institution, two-thirds of the respondents defined it in relation to either resource management or some form of input-output measure. Less than one-fifth of the respondents referred to efficiency in the value for money terms. For instance, a University in the Czech Republic highlighted the following: "We perceive efficiency as a managerial approach, which enables us to get more and better output using existing resources." In a similar way, a University in Austria expressed that efficiency is about: "Providing services in teaching and research with a minimum of input to get the best, or at least appropriate, results." The last example is from a University in the UK: "Efficiency is understood as the process of achieving the best possible results considering the results available, in order to fulfil the needs of the stakeholders and continuously improve the organisation's performance."

\section{Productivity Versus Value for Money}

Considering the multitude of interpretations, the existing theoretical and practical approaches to efficiency in the higher education context can be roughly divided into two groups:

(1) Resource-oriented approach, focusing on productivity of university operations and the extent to which an activity achieves its goal whilst minimising resource usage

The first group of definitions particularly emphasises the relationship between the obtained outputs compared to the used inputs. According to Hoenach (1982), "faculty, students, and other participants in higher education make choices that determine whether those resources will be used efficiently or inefficiently" (Hoenach 1982, p. 403). Thus, the central question is whether one system or organisation could achieve better results with the same or fewer resources. Hoenach's definition underscores that efficiency is the responsibility of individuals and organisations participating in higher education and that it should be judged according to the level of inputs used to attain them. Therefore, efficiency requires the detailed measurement of performance, whether on individual, departmental, institutional, or system level. In higher education, productivity is often measured based on the number of students (educated) per faculty member or the number of journal articles published per researcher (Salerno 2011). However, this leads to additional challenges, because assessments and comparisons require a clear knowledge of what those results should have been. 
(2) Value-based approach, placing emphasis on the outcomes achieved for end users, including students, employers, local community and society as a whole, for the cost of a product or service.

The second group accommodates a broader set of definitions that focus on both tangible and intangible effects of efficiency which could be experienced by a broad range of actors over different time horizons. In this context, efficiency concerns how resources are utilised in order to promote society's objectives as fully as possible (Lockheed and Hanushek 1994).

The value-based approach has been taken forward in the UK with the establishment of the Modernisation and Efficiency Task Group. Set up by Universities UK in 2011, this task group conducted extensive consultation with the sector and with key public and private sector stakeholders in order to explore what drives efficiency in the sector (Universities UK 2011). In the first step, the group suggested to look beyond short-term savings and view efficiency "as part of a wider strategic objective to enhance the effectiveness of institutions and ensure they continue to deliver high quality teaching and research" (Universities UK 2011). Subsequently, this broader approach linking efficiency and effectiveness evolved towards the concept of value for money in light of the growing accountability of universities towards their students, as fee-paying customers, as well as funders and taxpayers. Thus, value for money incorporates three elements such as economy (reducing the costs of inputs), efficiency (getting more output for the same or less input) and effectiveness (getting better at what universities set out to do). In other words, value for money is viewed as the achievement of economy, efficiency and effectiveness in how the university acquires and uses its resources in order to meet its objectives (Universities UK 2015).

Various examples show that all three elements-economy, efficiency and effectiveness - are equally important in the higher education context. While costs can, for instance, be reduced by closing facilities or the campus at a certain time of the year, such measures are not always effective since they could potentially be disruptive for the achievement of the university's goals. At the same time, universities may be highly efficient in operations but face constraints in terms of dropout or graduates' preparedness for work. Considering the unique combination of the university's tasks, the wrong balance of efficiency and effectiveness can bear significant risks for the institutions.

\section{Multifaceted Approach to Efficiency}

As shown above, efficiency is a complex concept, and few conceptual tools are in place to study it in the higher education context. The discussion on efficiency is also challenged by the diversity of approaches and interpretations. Therefore, it is suggested to view the topic through the prism of various levels and dimensions of efficiency that correspond to the core university settings. 


\section{Levels of Efficiency}

Efficiency can be dealt with at three different levels presented below:

- System (national or regional) level, which is associated with the framework conditions put in place for efficiency-related activities of universities by national governments;

- Sector level, which involves joint activities pursued by university networks/ collaborations/partnerships, often in cooperation with other stakeholders. Cooperation at this level spans across national frameworks of higher education and can involve a large number of actors with varying needs and interests;

- Institutional level (including faculty, departmental, and individual levels), which covers various activities of higher education institutions related to the design and implementation of institutional efficiency agendas.

When it comes to the system level, the ability of universities to act strategically and innovate can be enabled by government policies, in particular, through institutional autonomy. The Modernization Agenda of the European Commission (2011) directly links institutional autonomy to efficiency: "The efficiency of higher education institutions and so the effectiveness of public investment can be enhanced by reducing restrictions: on raising private revenue, on capital investment, on the ownership of infrastructure, on the freedom to recruit staff, on accreditation. Investment in professional management can provide strategic vision and leadership while allowing teachers and researchers the necessary academic freedom to concentrate on their core tasks". The level of organisational, financial, staffing and academic autonomy (Pruvot and Estermann 2017) underpins the university's margin for manoeuvre with efficiency. For example, a high degree of organisational autonomy reflected in the capacity to create for-profit legal entities enables university consortia to share housing or other services through a commercial subsidiary. Likewise, greater financial autonomy expressed in the ability to own and sell real estate supports the university's efforts to redesign campus based on space optimisation or similar initiatives.

As part of financial autonomy, modalities of public funding have a direct impact on institutional efficiency agendas. While public funding arrangements significantly vary across Europe, block grants remain the main method of public funding distribution in most of the countries in Europe (Pruvot et al. 2015). The EUA Public Funding Observatory 2017 (PFO) has captured significant reductions in public funding to universities in the period between 2008 and 2016. Of 34 higher education systems in Europe, only in three countries, that is Austria, Norway and Sweden, the volume of public funding to universities grew faster than student number between 2008 and 2016. All other countries included in the analysis were found to either make insufficient investments in higher education institutions compared to their student population growth or keep reducing public allocations (Pruvot et al. 2017). 
Whether countries maintain, increase or decrease public investment in the university sector, institutions are pressed to enhance efficiency and deliver more for the resources they get. Thus, policymakers increasingly link funding to institutional performance, e.g. through performance-based funding mechanisms, to increase the overall transparency of spending and incentivize the achievement of specific policy goals (Pruvot et al. 2015). In addition to shifts in public funding modalities, public authorities sometimes justify budget cuts with the need to incentivize institutions to operate more efficiently (Estermann and Kupriyanova 2016).

When it comes to the institutional level of efficiency, the role of leadership is essential at all stages. Support from senior management contributes to the development of a culture that highlights individual performance and achievement. The governors can also play an important role by promoting a strategic approach to efficiency and value for money, fostering a culture where innovation and improvement are encouraged and valued, and embedding efficiency into decision-making. For this purpose, data collection and analysis provide a clear steer on what needs to be shown to government and funders and inform the development of institutional systems and approaches.

\section{Efficiency Dimensions}

In addition to the various levels of action, efficiency can be explored through several dimensions as classified in the USTREAM project approach.

(a) Operational efficiency (efficiency in professional, operational and support services)

Operational efficiency is driven by the need to streamline business processes and optimise the use of resources. It combines a broad range of activities or measures performed to ensure the efficient implementation of day-to-day university operations, including facility and space management, procurement, finances, HR management and student support services. Operational efficiency measures can result in internal institutional reorganisation or institutions sharing resources, so optimising their operations. An overview of various operational efficiency measures is presented in Fig. 1.

(b) Efficiency in academic matters (efficiency in research, teaching and learning) Efficiency in academic matters embraces processes associated with the organisation of teaching and research. Examples include optimisation of the academic offer, digital learning and use of ICT for teaching and learning, and research profiling, among others. The question of academic efficiency arises on all institutional levels, including faculty and departmental levels and concerns the individuals involved in the research and teaching activities. Institutional measures in this area can include the definitions of teaching load, class sizes, and research output requirements. 


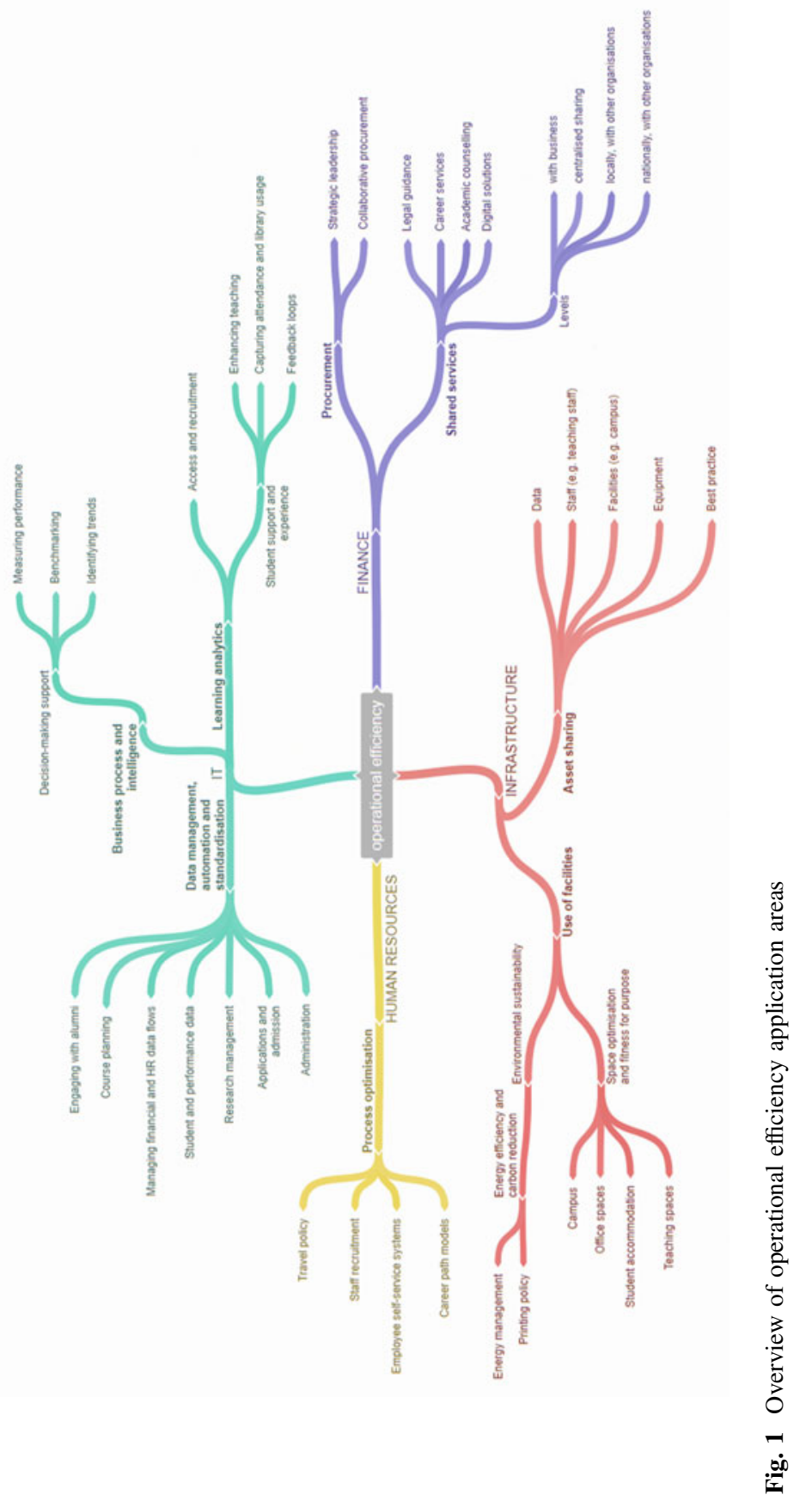


Table 1 Efficiency matrix - examples of efficiency measures

\begin{tabular}{l|l|l|l}
\hline $\begin{array}{l}\text { Level/ } \\
\text { dimension }\end{array}$ & Operational & Academic & $\begin{array}{l}\text { Strategic } \\
\text { governance }\end{array}$ \\
\hline $\begin{array}{l}\text { System/ } \\
\text { frameworks }\end{array}$ & $\begin{array}{l}\text { Land use, estate } \\
\text { ownership and } \\
\text { VAT regulations }\end{array}$ & $\begin{array}{l}\text { Programme certification } \\
\text { procedures }\end{array}$ & $\begin{array}{l}\text { Institutional } \\
\text { autonomy } \\
\text { legislation } \\
\text { Funding } \\
\text { modalities }\end{array}$ \\
\hline Sector & $\begin{array}{l}\text { Joint procurement } \\
\text { Shared services }\end{array}$ & $\begin{array}{l}\text { Sharing of research assets (e.g. } \\
\text { equipment, data); sharing of staff } \\
\text { (e.g. teaching staff) }\end{array}$ & $\begin{array}{l}\text { Exchange of } \\
\text { best practices, } \\
\text { peer learning }\end{array}$ \\
\hline Institutional & $\begin{array}{l}\text { Space use } \\
\text { optimisation } \\
\text { Centralised } \\
\text { procurement } \\
\text { Asset sharing } \\
\text { within institution }\end{array}$ & $\begin{array}{l}\text { Research profiling } \\
\text { Review of the academic offer }\end{array}$ & $\begin{array}{l}\text { "Efficiency } \\
\text { culture" } \\
\text { Leadership and } \\
\text { engagement } \\
\text { Value for } \\
\text { money reports }\end{array}$ \\
\hline
\end{tabular}

(c) Efficiency in strategic governance

Efficiency in strategic governance is associated with a broad range of activities related to the articulation of efficiency in the context of the value creation model to underpin performance management and institutional development; accountability and stewardship for institutional capital (financial, intellectual, human, relationship, natural, reputational, etc.); development of institutional "efficiency culture" based on leadership and staff engagement, investment in skills, technology and capacity-building; effective internal communication; engagement of governing bodies; stakeholder perception of value and integrated reporting (e.g. through value for money reports). Most activities in this area have a long-term nature based on a strategic, coherent and sustainable approach to efficiency, effectiveness and value for money which supports the institution-wide development.

Examples of common efficiency measures pursued by the sector are presented in a matrix, crossing three levels and three dimensions of efficiency (Table 1).

The next section provides an overview of efficiency trends and practices from the institutional perspective.

\section{Institutional Practices and Trends}

\section{Governance and Management of Efficiency}

\section{Key Institutional Actors Involved in Design and Implementation}

Efficiency is a topic reflected in institutional development strategies. In $93 \%$ of the cases, efficiency related considerations and activities were outlined in the 
Table 2 Importance of units involved in implementation of efficiency measures

\begin{tabular}{lccccc} 
& $\begin{array}{c}\text { Not at all } \\
\text { important }\end{array}$ & $\begin{array}{c}\text { Slightly } \\
\text { important }\end{array}$ & $\begin{array}{c}\text { Moderately } \\
\text { important }\end{array}$ & $\begin{array}{c}\text { Very } \\
\text { important }\end{array}$ & $\begin{array}{c}\text { Extremely } \\
\text { important }\end{array}$ \\
\hline Finance department & $1 \%$ & $4 \%$ & $18 \%$ & $44 \%$ & $32 \%$ \\
HR department & $0 \%$ & $6 \%$ & $25 \%$ & $46 \%$ & $22 \%$ \\
Central administration/operations & $0 \%$ & $5 \%$ & $11 \%$ & $52 \%$ & $33 \%$ \\
Faculties or departments & $1 \%$ & $1 \%$ & $26 \%$ & $46 \%$ & $25 \%$ \\
Dedicated office, entity or working group & $12 \%$ & $5 \%$ & $25 \%$ & $44 \%$ & $14 \%$ \\
\hline
\end{tabular}

institutional strategic plans, and $7 \%$ of the responding institutions are currently discussing how to address efficiency at the level of the entire institution. The design and strategic planning of efficiency measures typically fall under the responsibility of the rector or vice-rectors (81\%), followed by heads of administration (59\%), whereas governing bodies, such as councils or boards of trustees (44\%), are less involved in the design and planning of efficiency. Other institutional actors involved include deans or vice-deans, heads of department, strategic planning offices and management teams $(23 \%)$. When it comes to the implementation of efficiency measures, all institutional units seem to have an equally important role, although the reported relevance of a dedicated entity or working group is somehow lower (Table 2).

\section{Efficiency Targets and Evaluation of Outcomes}

In total, $78 \%$ of the respondents indicated that their institution evaluates efficiency which in $60 \%$ of the cases means an assessment at least once in a year. The identification of efficiency related indicators and their monitoring are most commonly done through the institutions' strategic planning process and annual reports. As a university from Portugal noted, the "monitoring of the strategic plan, namely evaluation of goals, of key performance indicators, results, and the level of implementation of the action plans, through internal audits, external audits, annual self-assessment" is key to assessing whether the university is efficient. Evaluation of efficiency can also be conducted by external bodies. "Every five years, an external commission mandated by the Ministry implements an evaluation on the basis of visits at the university and of a self-assessment report. The self-assessment process is implemented by the university and associates a large number of colleagues and functions." This example from a French case demonstrates the important role public authorities and national regulations can have in the evaluation of institutional efficiency.

Most of the institutions that responded to the survey reported to have performance targets set for teaching and research (79\% of all responding institutions), and a similarly high number $(76 \%)$ reported to have financial targets. Fewer institutions (42\%) have defined targets concerning productivity, and only $7 \%$ of all respondents 
indicated that their institution did not specify any targets to be achieved. Besides the mentioned ones, a couple of institutions have also set efficiency targets in the area of sustainability, organisational reputation, and management. While in the majority of the cases efficiency targets are identified and set by the institutions themselves, some respondents also highlighted the important role that national and regional authorities and even stakeholders play in this process.

\section{Drivers of Efficiency}

As outlined in the analytical framework, efficiency can be enabled or hindered as a consequence of developments at various levels. When asked what drives the efficiency agenda in their home institutions, most of the respondents highlighted external factors that push institutions to look at efficiency such as budget cuts and decreasing resources, new institutional approaches, and national and regional reforms. Nevertheless, internal institutional changes were marked as another important driver of efficiency. The least important in this regard were European policies and provisions (Table 3). Besides the offered choices, several institutions highlighted increased competition, stakeholder influence, and performance contracts as being important drivers of the efficiency agenda.

When it comes to the system level factors, such as public funding, it was observed during the site visits and interviews that, in those systems that experience significant public cuts, universities are often prompted to pursue institutional efficiency programmes focusing on short-term operational gains and savings. At the same time, institutions that are not exposed to funding cuts but experience the accelerated sector growth (e.g. reflected in the rapidly increasing student body) tend

Table 3 Drivers of efficiency

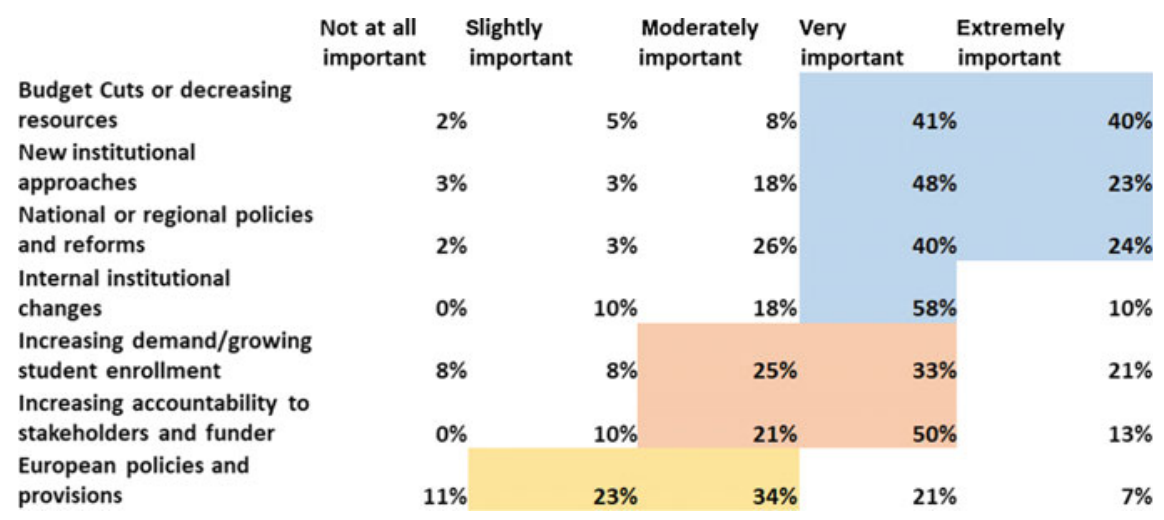


to pursue measures with a broader impact aiming to provide an institutional response to the system changes in a longer term.

\section{Implementation of Efficiency Measures: Barriers and Enablers}

The analysis of the applied efficiency measures shows that universities are particularly active in pursuing operational efficiency (mentioned by $89 \%$ of respondents), whereas fewer practices are reported concerning academic efficiency (78\%) and efficiency through strategic governance $(72 \%)$.

When looking at the importance of the implemented measures, the survey found that those institutions $(56 \%)$ that have streamlined the use of ICT in teaching have ranked this efficiency-oriented measure as relatively important. On the other end, $60 \%$ of responding institutions optimised their academic offer, yet most of them rated this measure as relatively unimportant. In addition to the offered concrete examples, institutions also emphasized the importance of efficiency-oriented measures in the area of student services and in managerial and administrative processes. Good practices in academic efficiency show benefits gained from encouraging academic community to review the academic offer, provide cost estimates for a course, and engaging students in course design. Mixed outcomes are reported on the use of internal performance-based funding for research and benchmarking.

Institutions that wish to increase their efficiency face numerous challenges. Three barriers stood out to be very or extremely important for at least half of the responding institutions. Among them, the institutional culture and the reluctance to change were rated as the most prominent barriers to implementing efficiency measures. Financial constraints and concerns over quality were also perceived as important obstacles. In contrast, legal barriers and technical obstacles were rated the least important for efficiency measures (Table 4). Besides the outlined ones, participants also mentioned resistance from trade unions, lack of staff motivation, limitations of the organisational structure, and the lack of external pressure for increasing efficiency.

The respondents also rated the importance of factors that enable the implementation of efficiency measures. Four factors were perceived as very or extremely important by more than two-thirds of all responding institutions. These were the commitment of the institution's leadership, institutional autonomy, inclusiveness and participation of all relevant institutional actors, and raising awareness regarding the importance of efficiency. The two factors that most institutions reported to be somewhat less important are external financial support and external expertise (Table 5). 
Table 4 Barriers to efficiency

\begin{tabular}{lccccc} 
& $\begin{array}{l}\text { Not at all } \\
\text { important }\end{array}$ & $\begin{array}{l}\text { Slightly } \\
\text { important }\end{array}$ & $\begin{array}{l}\text { Moderately } \\
\text { important }\end{array}$ & $\begin{array}{l}\text { Very } \\
\text { important important }\end{array}$ \\
\hline $\begin{array}{l}\text { Institutional culture / } \\
\text { reluctance to change }\end{array}$ & $3 \%$ & $5 \%$ & $20 \%$ & $38 \%$ & $34 \%$ \\
$\begin{array}{l}\text { Financial constraints } \\
\text { Concerns over quality }\end{array}$ & $9 \%$ & $9 \%$ & $22 \%$ & $36 \%$ & $23 \%$ \\
$\begin{array}{l}\text { Lack of expertise or qualified staff to } \\
\text { implement the measures }\end{array}$ & $6 \%$ & $12 \%$ & $27 \%$ & $43 \%$ & $12 \%$ \\
$\begin{array}{l}\text { Technical obstacles } \\
\text { Legal barriers }\end{array}$ & $9 \%$ & $12 \%$ & $34 \%$ & $33 \%$ & $12 \%$ \\
\hline
\end{tabular}

Table 5 Enablers of efficiency

\begin{tabular}{|c|c|c|c|c|c|}
\hline & $\begin{array}{l}\text { Not at all } \\
\text { important }\end{array}$ & $\begin{array}{l}\text { Slightly } \\
\text { important }\end{array}$ & $\begin{array}{l}\text { Moderately } \\
\text { important }\end{array}$ & $\begin{array}{l}\text { Very } \\
\text { important }\end{array}$ & $\begin{array}{l}\text { Extremely } \\
\text { important }\end{array}$ \\
\hline $\begin{array}{l}\text { Commitment of institutional } \\
\text { leadership }\end{array}$ & $0 \%$ & $2 \%$ & $10 \%$ & $44 \%$ & $44 \%$ \\
\hline Institutional autonomy & $0 \%$ & $3 \%$ & $14 \%$ & $41 \%$ & $42 \%$ \\
\hline $\begin{array}{l}\text { Inclusiveness and participation of } \\
\text { all relevant institutional actors in } \\
\text { the process }\end{array}$ & $0 \%$ & $6 \%$ & $15 \%$ & $48 \%$ & $31 \%$ \\
\hline $\begin{array}{l}\text { Raising awareness of efficiency } \\
\text { and training for staff }\end{array}$ & $0 \%$ & $6 \%$ & $22 \%$ & $51 \%$ & $21 \%$ \\
\hline $\begin{array}{l}\text { External financial support (e.g., } \\
\text { public or private) }\end{array}$ & $3 \%$ & $20 \%$ & $27 \%$ & $34 \%$ & $16 \%$ \\
\hline $\begin{array}{l}\text { External expertise (e.g., through } \\
\text { external board members, partners, } \\
\text { consulting) }\end{array}$ & $2 \%$ & $14 \%$ & $37 \%$ & $37 \%$ & $11 \%$ \\
\hline $\begin{array}{l}\text { Cooperation with other } \\
\text { institutions, peer-learning }\end{array}$ & $0 \%$ & $25 \%$ & $30 \%$ & $40 \%$ & $5 \%$ \\
\hline
\end{tabular}

\section{Impact of Efficiency Measures}

Various institutional actors may react differently to the implemented efficiency measures. As shown in an earlier example, an action that is considered necessary by the management of the institution to increase efficiency might, at the same time, be regarded inefficient or ineffective by other actors. To shed some light on this dilemma, the study asked participants of the online survey to identify the impact of efficiency measures on the institutional goals in the areas of teaching, research, internationalisation, and services, value for community and economy. The results of the survey show that the majority $(83 \%)$ of the respondents identify significantly positive or some positive impact in this regard. However, this finding has to be considered with caution taking into account possible bias, given that the 
respondents primarily come from the offices that are involved in the design and implementation of efficiency measures. Hence, further research on the effects of efficiency on the university is needed particularly in a longer-term outlook.

\section{Discussion and Conclusions}

The analysis of theoretical and practical approaches to efficiency reveals a great diversity in terms of interpretations and perceptions of efficiency as well varying degrees of engagement with the topic. There is a common understanding that the specific nature of higher education requires addressing efficiency in balance with effectiveness and value for money.

Considering the changes in the academic landscapes, efficiency will likely remain one of the relevant topics on the higher education agenda, and it has, therefore, to be viewed pragmatically as a way to achieve the university's goals rather than a response to decreasing public funding. Saying that, it is necessary to stress that efficiency strategies must be supported by sufficient investment in highly skilled staff and modern technology which are needed for their implementation. In that spirit, sustainable public funding as well as greater institutional autonomy underpin the capacity of institutions to improve the efficiency of processes in the long term.

The reinvention of efficiency based on a more balanced approach that looks at various levels and dimensions of efficiency requires a continuous dialogue and communication both internally, within the institution, and with external stakeholders (e.g. by means of peer learning and benchmarking). Such communication is particularly needed to manage expectations about the outcomes that could be achieved through the implementation of various efficiency agendas. In this respect, both institutions and policymakers should be aware of the limits to replicability, transferability and measurability of efficiency measures and therefore engage in an open dialogue on such limitations and preconditions of efficiency in order to avoid any conflicts. Replicability and transferability of efficiency measures can be limited not only by the specific system-level or institutional conditions but also by the nature of measures, which can, for instance, be implemented as "one-time" actions and quickly deplete their saving or optimisation potential.

Measuring the success of efficiency activities can also be problematic considering more intangible and often unexpected effects of efficiency that might be perceptible in a longer run, as well as different ways to calculate the gains or losses. For instance, office rearrangement initiatives aimed at optimising the use of space were found in some cases to improve internal coordination and collaboration, reducing the need for formal meetings. Such effects are difficult to measure or monetise.

Furthermore, the range of drivers that universities can rely on as unique social systems to foster and evaluate progress is broader and more original than economic ones. For instance, intrinsic motivation can be a strong driver for efficiency, 
effectiveness and value for money across the entire institution, provided that all institutional actors participated in the efficiency processes, and peer-to-peer exchanges and evaluation provide another way to evaluate success. The meaning of such measures inspired by the university's tradition should be translated for other actors, particularly funders (e.g. ministries of finance), which may not be familiar with the original qualitative approaches applied in the academic context.

Finally, standardisation, which is the starting point of many efficiency programmes, has also its limits for the implementation in the diverse and highly autonomous university context. In this context, both leadership and a continuous engagement of all institutional actors into the process are key to ensure the success of efficiency strategies.

Our study of institutional practices shows that the European higher education sector already demonstrates a high level of maturity in terms of operational efficiency with a variety of practices applied. Examples of good practices in academic efficiency show benefits gained from encouraging the academic community to review the academic offer, or provide cost estimates for a course, as well as from engaging students in course design. The potential in the area of academic efficiency is significant, although due attention should be paid to possible tensions between academic freedom and efficiency. Practical ways to overcome this tension need to be further explored. Further room for progress in the different efficiency settings is associated with streamlining efficiency activities through an improved strategic governance and pursuing a more coordinated cross-institutional approach based on collaboration and peer learning.

Acknowledgements The authors of this paper are grateful to all partners of the USTREAM project for their continuous support and guidance on the topic. We would like to thank the research team of the Central European University led by Liviu Matei, particularly, Agnes Leyrer for her contribution to the literature review, and Kata Orosz for her assistance with the analysis of the survey data. We would also like to thank Jamie Arrowsmith and Max Hastings from Universities UK for their insights into the UK higher education developments as well as Michael Casey from the Irish University Association. We are grateful to all the participants of the USTREAM surveys and interviews, with special thanks going to our colleagues from the national rectors' conferences, particularly Universities Austria (UNIKO), Conference of Rectors of Academic Schools in Poland (KRASP) and the Flemish Interuniversity Council (VLIR). Finally, this work would not have been possible without the financial support of the Erasmus + programme of the European Union.

\section{References}

Pruvot, E. B., Claeys-Kulik, A., \& Estermann, T. (2015). Designing Strategies for Efficient Funding of Universities in Europe. Brussels: European University Association.

Pruvot, E. B., \& Estermann, T. (2017). University Autonomy in Europe III. The Scorecard 2017. Brussels: European University Association.

Pruvot, E. B., Estermann, T., \& Kupriyanova, V. (2017). EUA Public Funding Observatory 2017. Brussels: European University Association. 
Broucker, B., de Wit, K., \& Leisyte, L. (2015). An evaluation of new public management in higher education. Paper presented at the EAIR 37th Annual Forum 30 August-2 September 2015, Krems, Austria.

Clark, B. R. (1998). The entrepreneurial university: Demand and response. Tertiary Education and Management, 4(1), 5-16.

Estermann, T., \& Kupriyanova, V. (2016). EUA Public Funding Observatory 2016. Brussels: European University Association.

European Commission. (2011). Modernisation Agenda Supporting growth and jobsan agenda for the modernization of Europes higher education systems.

Hoenach, S. A. (1982). Pricing and Efficiency in Higher Education. Journal of Higher Education, 53(4), 403-418.

Lockheed, M. E., Hanushek, E., \& Washington, D. C. (1994). Concepts of educational efficiency and effectiveness Human resources development and operations policy working papers no HRO 24 World Bank. Washington, DC: World Bank.

Peters, M. (1992). Performance and accountability in 'post-industrial society's: The crisis of British universities. Studies in Higher Education, 17(2), 123-139.

Reichert, S. (2009). Institutional Diversity in European Higher Education, Brussels: European University Association. Brussels: European University Association.

Sadlak, J. (1978). Efficiency in higher education — concepts and problems. Higher Education, 7(2), 213-220.

Salerno, C. (2011). What We Know about Efficiency of HE Institutions: the Best Evidence, Enschede: Center for Higher Education Policy Studies University of Twente (CHEPS).

Universities UK. (2011). Efficiency and effectiveness in higher education: A report by the Universities UK Efficiency and Modernisation Task Group.

Universities, U. K. (2015). Efficiency, Effectiveness and Value for Money.

Open Access This chapter is licensed under the terms of the Creative Commons Attribution 4.0 International License (http://creativecommons.org/licenses/by/4.0/), which permits use, sharing, adaptation, distribution and reproduction in any medium or format, as long as you give appropriate credit to the original author(s) and the source, provide a link to the Creative Commons license and indicate if changes were made.

The images or other third party material in this chapter are included in the chapter's Creative Commons license, unless indicated otherwise in a credit line to the material. If material is not included in the chapter's Creative Commons license and your intended use is not permitted by statutory regulation or exceeds the permitted use, you will need to obtain permission directly from the copyright holder. 